\section{LA CRÍTICA DE ARTE EN COLOMBINE. EL CONCEPTO DE BELLEZA}

\author{
María Victoria Gómez Alfeo \\ y Fernando García Rodríguez \\ Universidad Complutense de Madrid \\ c/ Rector Royo Villanova, n. ${ }^{\circ}$ 10, Portal 3, 7. ${ }^{\circ} \mathrm{A}$. \\ 28040 Madrid \\ criticadearte@filos.ucm.es
}

\begin{abstract}
The relationship of Colombine with the art and with the artists it is continuous in their gatherings and in their trips, in those that the work, and the artist looks for, as deep manifestation of the culture that is about knowing. The defense of the Greek one registers in the campaign of the journalism to save the squares of San José's chapel. The valuations and descriptions of the Italian and flamenco art, their trip notes, project us to the relationship, always protected, between painters and poets. For everything it is attracted by us to it knowing their position before the work, that is to say, their concept of beauty that we have analyzed in their journalistic critics and in their books of trips.
\end{abstract}

KEY WORDS: Colombine; "Ut pictura poesis"; art critic; beauty; aesthetics; Art; the Greek one; Defense of the artistic patrimony.

\section{COLOMBINE AND THE ART CRITICISM ITHE BEAUTY CONCEPTI}

RESUMEN: La relación de Colombine con el arte y con los artistas es continúa en sus tertulias y en sus viajes, en los que busca la obra, y el artista, como manifestación profunda de la cultura que trata de conocer. La defensa del Greco se inscribe en la campaña del periodismo para salvar los cuadros de la capilla de San José. Las valoraciones y descripciones del arte italiano y flamenco, sus notas de viaje, nos proyectan a la relación, siempre defendida, entre pintores y poetas. Por todo ello nos atrae el conocer su posición ante la obra, es decir, su concepto de belleza que hemos analizado en sus críticas periodisticas y en sus libros de viajes.

PALABRAS CLAVE: Colombine; "Ut pictura poesis"; crítica de arte; belleza; estética; Arte; el Greco; Defensa del patrimonio artístico.

A Pilar Palomo

por su generosidad intelectual

lleva, en El País, la "ilustración" de las féminas, Antonio Asenjo, Julio Camba que cita en apoyo de sus tesis, en este asunto, al "maestro Cávia", Esteban Batlle y otros; aunque defendiéndole, y al frente de las huestes contrarias, Colombine, Fray Gerundio, en El Diluvio de Barcelona, El Padre Franco, Un Clérigo de esta Corte, claro que estos dos últimos son seudónimos de Ferrándiz, que cita, en apoyo de sus tesis, a Manuel Bueno. En esta tribuna, ingeniosamente periodística, se cita a los griegos, a Praxíteles, y, como no podía faltar, a Maura, para criticarle, claro, porque por alli no se encontraba Azorín.

José Ferrándiz, en "Madrid sin monumentos" (El País, 17/9/1905), deja explícito su programa estético, convertir Madrid en una Atenas clásica. Es importante la cita, ya 
que Colombine asume estos ideales estéticos en el arte y en la mujer, al menos, según hemos detectado en sus críticas en Heraldo de Madrid y en La Esfera, hasta el año 1914, fecha en la que vemos un giro en su concepto de belleza femenina. Pepín Ferrándiz, en 1906, publica, en El País, (4/10/1906) un artículo con el título "El progreso de lo feo". El articulejo, en expresión del propio Ferrándiz, va a recibir respuesta, desde las mismas páginas de El País, por un joven periodista, que pronto cobrará merecida fama, Antonio Asenjo, que titula "De caleología. Lo bello progresa" (El País, 8/10/1906) Tomando la afirmación de que "la hermosura nacional aumentaba o por lo menos no decrecía", observación que hizo de muchacho, Asenjo lanza un disparo sin misericordia a este terrible Ferrándiz: "Ve usted a las mujeres desde la altura de sus respetables cincuenta años". Para Aristóteles, Retórica, "La belleza es diferente en cada edad". El artículo de Asenjo es demoledor y algunos párrafos hirientes contra Ferrándiz. La respuesta no se hace esperar, José Ferrándiz, titula, "De estética humana" (El País, 11/11/1906) La querella sobre la belleza no acaba más que comenzar. Julio Camba (El País, 12/10/1906) entra en la polémica y sitúa su importancia en el primer párrafo: "El artículo del padre Ferrándiz sobre belleza colectiva, es, para mí, muchísimo más trascendental que todas sus notables campañas anticlericales", cita a Violeta -que hace la crítica de moda femenina en El País-, y a Asenjo. Sobre el artículo de Violeta escribe que "para decir que la belleza femenina es una encantadora realidad, holgaba toda palabra. Su sola presencia lo hubiera demostrado plenamente" ("mostrado", apostillamos nosotros, querido Asenjo, no demostrado. Violeta es una realidad, y la demostración es una actividad lógica del pensamiento), y afirma que "poco a poco se ha ido formando un tipo de gracia, de arte y de malicia". La expresión, la gracia, la elegancia son atributos de la belleza y por los cuales decimos que una cosa es, o puede ser, bella. Tratemos de adjetivar a las "mujeres" de Penagos y estos adjetivos estarán presentes, además de picardía, juventud, y "demi mondente", como cantan en la zarzuela Alma de Dios; Asenjo finaliza rechazando la belleza modernista: "yo necesito decirle dos cosas: que no soy modernista y que mi ideal de Belleza no lo constituye precisamente una cosa larga y triste con pelos de alambre". Llegada la polémica a este punto entra, en apoyo de Ferrándiz, Colombine, con un artículo extenso, ditirámbico en sus comienzos, y titula: "Femeninas. La belleza humana" (Heraldo de Madrid, 30/10/1906): "Anda estos días rodando por la Prensa una interesante discusión, que la galana pluma de Ferrándiz lanzó a la palestra en uno de sus hermosos artículos... Que lo hermoso es siempre amable no cabe dudarlo; se siente una emoción purisima de un orden elevado e inmaterial ante lo verdaderamente bello, la belleza decrece de un modo alarmante. Son muchas las causas que concurren a ello". La influencia de la religión es vista como uno de los factores fundamentales para constatar que "la belleza de la forma humana decrece: La razón es sencilla: desaparecieron los baños, masajes y unciones fortificantes de las religiones que tenian su culto en la belleza y el placer; vinieron los días en que el cuerpo fue mirado como enemigo digno de castigo o como fiera indómita, que era preciso aniquilar para no ser devorado por ella. Y el ayuno, los cilicios y la falta de limpieza fueron destruyendo las formas amplias y sanas"1. Concede tanta importancia a este párrafo que lo copia en Por Europa (1907, 152). Finaliza el artículo: "Por eso yo, en este pleito que hoy se suscita, lamentándolo sinceramente, creo que, en efecto, la belleza de la forma humana decrece, y su negación, la fealdad, si no se la combate activamente, traerá la degeneración completa del Arte, primero, y de la Humanidad después". La dedicatoria, y otras citas, de Por Europa, muestra la relación, en amistad y pensamiento, entre Carmen de Burgos y Ferrándiz al que llama "admirado maestro: Todos conocen en España, y fuera de ella, al valiente cronista de El País, maestro de la juventud sana, al que sabe demoler, con mano firme, prejuicios y tiranías... sigue siendo su vida demasiado pura para Ilamarla sacerdotal, y todos han de confesar que el teólogo combatiente contra los absurdos de la teología es un hombre honrado". Al llegar a Italia, exclama "iltalia! jltalia! Amigo mío: no sé cómo escribir a usted la primera carta desde la tierra de mis ensueños." (Colombine, 1907, 167), y, ante la inminencia de la tragedia del Vesubio, una vez más, se dirige a Ferrándiz: "Mejor que carta, amigo Ferrándiz, esta es una postdata a mi anterior." (Colombine, 1907, 296).

Bello lo aplica, indistintamente, a una visión del sol cuando rie "entre los hilos de la trama de las velas de las embarcaciones"; a la distinción entre un espectáculo grandioso sin ser bello; de una ciudad (La Esfera, 3/5/1930); la belleza en la mujer; "el gran lago de Brujas es como el amor bello y triste, dulce é inquietante; son bellos los paseos de árboles, al lado de un hermoso canal de aguas inmóviles; un retrato es bello el día en que se hace, cuando nos sirve de espejo, cuando nos presenta á la persona querida tal como está actualmente en nuestro recuerdo" (Colombine, 1912, 
18) Frente al subjetivismo de la estética contemporánea, Colombine acepta, o se decanta, por el objetivismo de la Gran Teoria: "hay en nosotros un sentimiento, más o menos educador, que nos dice con elocuencia irrefutable: "Eso es hermoso o eso es feo" (Heraldo de Madrid, 30/10/1906). Frente a la modernidad, fragmentadora, individualista y estéril opone el clasicismo. En esta disputa, se encuentran posiciones que han sido la base de controversias en torno a la concepción del arte, de la estética y de la crítica de arte; entendemos, que es uno de los asuntos más complejos de nuestra contemporaneidad, por ello, y en un intento de sintesis, decimos que "una obra de arte sólo se puede comprender objetivamente dentro de cierta subjetividad sintonizada con la obra..." (Von Balthasar, 1961, 447s.) El artículo de Colombine no gusta a Antonio Asenjo (El País, 6/11/1906) que responde a Ferrándiz y deja esta perla para Carmen: "Termino, pues, haciendo constar que no he dicho nada del artículo de la bella escritora Colombine, porque puede en mí más la galantería que nada".

En los críticos de arte de este período se detecta un gusto por "lo clásico", una defensa de los ideales y de la belleza griega. El apotegma de d'Ors es conocido y nos exime de otras citas: lo que no es clásico es plagio. Colombine, en Montmartre, afirma que "la belleza vivirá siempre". En el Louvre, la descripción de la Venus de Milo expresa toda su admiración hacia el ideal de belleza clásica. Es difícil sustraerse a la belleza de esta descripción: "Venus de Milo altiva y risueña, sensual y casta, incitante y púdica, con su blancura de mármol y sus líneas de hermosura suprema está la inmortal Afrodita, con todo el esplendor de su imperecedera belleza... Esta Venus es la Diosa del amor, del amor eterno que canta la naturaleza y la fecundidad; es la belleza suprema" (Colombine, 1907, 62); Platón, en el Fedro, está citado implícitamente. En El veneno del arte, refuerza este criterio: "el caso de la bella Julieta Recamier, encerrándose en vida en los salones de su palacio como en los muros de una tumba. Nadie vio marchitarse la belleza de aquel rostro ideal" (Colombine, 1910, 16).

Por Europa, Colombine viaja, según propia confesión, cargada de libros. No tenemos constancia de qué autores se trata, pero, en las descripciones y apreciaciones de obras de arte, podemos adelantar que conoce los textos de F. W. Schlegel, 1805; W. Goethe, 1816; Stendahl, 1817; Hegel, Estética, 1829; Ruskin, Padua, 1854, Florencia, 1877 (traduce obras al español); H. Taine, Voyage en Italie, 1866; E.
Fromentin, 1876, citado expresamente; M. Dvorak 1904. De Platón destacamos, por su explícita cita, Fedro y El Banquete. Es difícil pensar que una persona de su cultura, más aun, de sus preocupaciones, desconociera estos textos.

En sus viajes (realmente toda su vida es un viaje interior, del pensamiento, y exterior), se acerca a las obras $y$, además de las descripciones, que conforman una página importante de su pensamiento, nos deja comentarios fronterizos entre crítica y estética. Fronterizos en el pensamiento, pues se duele de las fronteras físicas levantadas por los hombres. El pensamiento de Taine está presente en esta reflexión: "Pero hay algo que no se puede arrancar de la tierra en que la obra nace: su espíritu. Sin conocer su ambiente, sus costumbres, su luz, su raza, no se puede conocer bien el mérito de una pintura... El arte es uno é indivisible; el encanto de los holandeses, quiero estudiar en su nación, aunque en Arte sea débil la frontera que de los flamencos los separa" (Colombine, 1912, 90) Años más tarde, insiste en este posicionamiento estético (La Esfera, 30/03/1918): "He buscado siempre los cuadros de los pintores primitivos, italianos y flamencos, en los museos de Italia y de los Países Bajos, como la fuente más pura del arte pictórico... es de los documentos más importantes para analizar el alma de un pais... Se puede juzgar el cuadro aislado, técnicamente, no comprenderlo ni compenetrarse con él por entero. Aun así hemos de realizar un esfuerzo prodigioso para retrotraernos á los tiempos en que se produjo. En el ensueño que nos acerca á ellos, aquí estamos más cerca de conseguirlo." (Colombine, 1912, 43) Esta actitud es de gran actualidad, en efecto, "la obra de arte es un punto de encuentro de los espíritus, un signo de enlace. El objeto figurativo es uno de los instrumentos de la toma de conciencia de toda sociedad." (Francastel, 1969, 15 y 103) y "todo arte es la trasposición de las necesidades y de las aspiraciones de la época en que nace" (Francastel, 1988, $63)$; con otras palabras, el objeto de estudio de la historia del arte es la obra de arte y su objetivo final es el conocimiento del hombre en sociedad, porque "todo artista toma en sus manos los hilos del desenvolvimiento, bajo la forma de una tradición decisiva, de una técnica históricamente adecuada, y de la actualidad de ciertos problemas y técnicas" (Hauser, 1961, 173); y desde la crítica, "Cada siglo, cada pueblo ha poseído la expresión de su belleza y de su moral" (Baudelaire 1846, 102); hemos elevado los museos a templos del arte, y no hemos reparado que al desgajar la obra de su razón de ser esta queda reducida a simple objeto

ARBOR CLXXXVI EXTRA JUNIO 2010 139-147 ISSN: 0210-1963

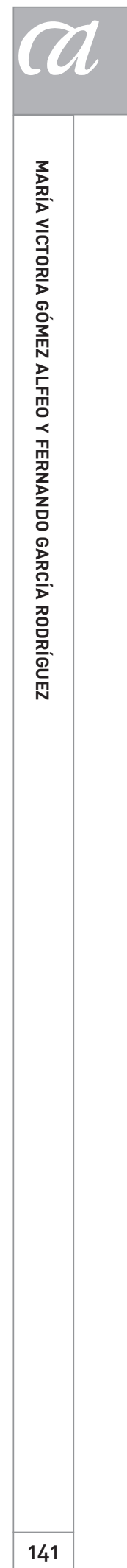


estético, sin contextualización, sin raíces, alejada del espíritu que la dio vida. Las calificaciones, en Colombine, son precisas y muestran la amplitud y preferencia de su gusto: "cuando el artista pone en la obra algo de su propia alma las diferencias enriquecen y hacen atractiva la contemplación..." La moderna crítica de arte, muy relacionada con la iniciada en el siglo XVIII, intenta transmitir la vivencia estética de la obra comunicada al espectador, o lector, por medio del lenguaje. En Colombine no hay ni una teoría ni una metodología previa, aunque la influencia de Hipólito Taine esté presente. El sentimiento será el único punto de partida, previo a la percepción artística, constituyéndose en empirismo artístico, o, más exactamente, estético. Es una actitud crítica y estética que merece reflexión. Charles Baudelaire proclama: "Creo sinceramente que la mejor crítica es la que es amena y poética... La mejor reseña de un cuadro podrá ser un soneto o una elegía" (Baudelaire, 1846, 101-102); Baudelaire rechaza la crítica positivista que quiere explicarlo todo y se despoja de toda clase de temperamento; Camón Aznar ( $A B C, 27 / 6 / 1962)$, finaliza este artículo, de la Tercera de $A B C$, con la proclamación de sus ideales en la crítica.

\section{Bases Conceptuales}

Si analizamos las categorias estéticas que aparecen en las críticas periodísticas, o en sus libros de viajes, es por una doble razón: en sí misma, como expresión de un juicio que contrastamos sobre esa obra y que con otros más configuran las diferentes apreciaciones que en distintos autores y épocas ha suscitado la obra, más aun, tratándose de la expresión del "gusto" de una escritora que se enfrenta a la obra y nos manifiesta sus tendencias y preferencias. Y, porque la categoría estética expresada permite aportar un juicio de valor estético de la obra, según que consiga o no el "género ideal" de la sociedad española del primer cuarto del siglo XX.

Tenemos presente que Colombine está en el centro de la sociedad intelectual y periodística de su época, lo que confiere a sus juicios de valor una importancia que queremos destacar. No ejerce la crítica de arte sobre exposiciones, ya que en Heraldo de Madrid el crítico es el respetado por todos Alejandro Saint-Aubin. No nos proponemos aquí someter a crítica estos argumentos, y preferencias de Co- lombine, y los juicios que de ellos se derivan; no porque los consideremos irrefutables, sino porque se trataría, en este punto, de escribir un enésimo playdoyer para añadirlo a los muchos y eficacísimos ya escritos. Es difícil soslayar, en persona de esta cultura, a los críticos españoles del momento con los que mantendría relación: Francisco Alcántara, Alejandro Saint-Aubin, Jacinto Octavio Picón; Jacinto Felipe Picón; C. Solsona; Antonio Cánovas y Vallejo; Ramiro de Maeztu; Eladio de Lezama; Julio R. Pedre; Pío Baroja; Luis Pardo.

\section{MIMESIS}

La idea del arte como imitación de la naturaleza es destacada por Colombine. El eterno ideal artístico se funda en la imitación de la naturaleza como fuente de todo progreso. Teoría aristotélica de la imitación. El término sintetizar es empleado frente al "concepto de la imitación", y, sobre todo, a ir mas allá de la simple verdad natural, en busca de la representación de la Belleza. Alberti dice que además de la semejanza hay que añadir belleza. Naturaleza y arte. La Naturaleza tiene interpretaciones muy diferentes que oscilan entre el pasado y el presente que se trata de descifrar: "el flamenco... copia a la Naturaleza de un modo insuperable, sin perdonar detalles ni modificarla, satisfaciendo su deseo de belleza plástica. Los ensueños son patrimonio de los latinos. Cuando quieren entregarse á la fantasía producen demonios y monstruos extraños, abortos de la imaginación en una kermesse infernal" (Colombine, 1912, 63). Colombine no cita al Bosco por estar, estética y anímicamente, lejos del "ocaso de la Edad Media", de la que es uno de sus más enigmáticos representantes. El retrato del duque de Alba es una de las descripciones que más nos han atraído de Colombine, por la relación texto-imagen, y por la posición ética, que podemos calificar de dramática: "Un cuadro inquietante es el de Antonio Moro... El prodigio es su cara... Se ve, como dice Fromentín, "todo un gran señor acostumbrado á prender grandes señores... Es preferible el tirano, si es fanático por convicción, al bon vivant que se pliega á las exigencias de la diplomacia según el partido que le conviene adoptar. Pero no divaguemos." (Colombine, 1912, 146). Su apasionado amor a la vida, a la libertad y a la belleza queda aquí mostrado. La descripción puede convertirse en una interpretación creadora. La traducción -o transposición de valores y elementos de una esfera 
de expresión a otra- poéticamente valiosa es al mismo tiempo una interpretación fecunda de la obra traducida; no repite algo ya existente, sino que crea una nueva figura, bajo cuya luz adquiere sentido la forma original (Pächt, 1986, 84). Años después, Juan de la Encina (Propósitos, La Voz, 2/7/1920) dejaría explicitadas sus preferencias, con las que estamos totalmente en sintonía estética y moral: Actitud estética: "Debemos advertir que entra más en nuestros gustos el modo de cualquier futurista estridente que no el de nuestros actuales y agarbanzados pintores de casa grande." Actitud ética: "Puestos en la obligación de elegir, preferimos siempre la anarquía a la librea". Lo reconocemos, con estas ideas podriamos formar todo un estudio, por lo que sugieren, por lo que expresan. Después de esta vivencia artística, Colombine supo más de sí misma. En nuestra palpitante actualidad, bon vivant podemos traducirlo por subjetivismo y nihilismo, sin forzar mucho el concepto ni la idea de Colombine.

\section{EXPRESIONISMO}

Colombine ("La Condesa Tolstoi", Heraldo de Madrid, 23/11/1904): "Con los ojos de fuego, la tez coloreada por la brisa, la boca entreabierta para respirar el aire puro y desbordándose de su toca los espesos rizos del cabello, que con el impulso de la carrera flotaban, azotando sus sienes y sus ojeras... su silueta se destacaba... como una Walkiria, una mensajera de Odín, que cabalgase en las nieves". Niza: "Otro lienzo atrajo mucho mi curiosidad más por la expresión de las figuras que por su mérito: Cristo y la Mujer Adúltera. Hay mucha belleza y mucha realidad en la actitud de aquella mujer de redondos brazos, fuertes caderas, ojos negros y rostro moreno, que cae a los pies del Salvador con los vestidos desgarrados, mostrando la carne exuberante que la indujo al pecado." (Colombine, 1907, 142).

\section{MOdeRnISMO}

Oposición al modernismo en arte y en la figura femenina (excluimos de nuestro análisis la literatura): "La reina de la moda era una marquesita italiana, pálida y quebradiza, que llevaba trajes flotantes. Una figura mística, alargada y pura; de largo cuello y manos transparentes; un cutis blanco de cera en un rostro iluminado por la llama violeta de unos ojos perversos, agrandados en las ojeras, que como un lirio azul se marcaban en su semblante." (Colombine, 1910, 10). La publicidad estimula para que las mujeres tengan "senos desarrollados, reconstituidos, hermoseados, fortificados" con las "Pilules Orientales". Suponemos que estos anuncios harían las delicias de los lectores. Rechazar el Modernismo, en los críticos de arte del primer tercio del siglo XX, lo podriamos resumir en la frase de don Miguel de Unamuno: "iLa impotencia! No conozco impotencia mayor que la que se oculta bajo eso que se llama modernismo. De originalidad ni chispa...". Pujalá y Vallés (Las Noticias, Barcelona, 15/2/1901) le contesta en un artículo donde la "chispa" está en todas sus líneas, y en la frase retórica shakespeariana repetida al final de cada argumento: "Pero el señor Unamuno dice que es impotencia y como quiera que es rector de la Universidad de Salamanca, debe tener razón." Don Pío (El Imparcial, 24/8/1903), ve su oportunidad: estar contracorriente.

\section{ARTE MOderno}

"Después de varios días de esta contemplación [Colombine hace referencia a los museos de Bruselas, Gante, Brujas], al pasar al museo moderno parece que el arte cae del cielo á la tierra. ¿Cómo hemos perdido la orientación hacia la belleza teniendo los modelos a la vista? Antes de hablar de este museo hemos necesitado borrar recuerdos y no establecer comparaciones... Esto no quiere decir que no existan cuadros muy notables en el museo moderno" (Colombine, 1912, 149). Y centra su análisis en Antoine Wiertz (Dinant, 1806-Bruselas, 1865) "Su pintura expresa el gusto por lo absurdo y horrible, intermedio entre el barroco de Rubens y el expresionismo y surrealismo, con obras macabras." Un ejemplo de cómo ejercer la información y crítica de arte, documentándose sobre el artista o la obra a comentar. En este caso, la atracción que la obra del pintor Wiertz ejerce sobre su espíritu es la desencadenante de la información, no una exposición o encargo de un periódico. El recuerdo de Baudelaire, y en España Margarita Nelken, nos sale al encuentro cuando proclaman que la crítica debe ser parcial, más aun, política. Un lector superficial extraeria la consecuencia de que Colombine no es de su tiempo. El siguiente párrafo es de una claridad que deslumbraría

ARBOR CLXXXVI EXTRA JUNIO 2010 139-147 ISSN: 0210-1963 
a don Pío y a Azorín (Ortega, El Sol, 26, octubre, 1924). Rechazo del academicismo:

"Los artistas de genio pesan demasiado sobre nosotros. Si vivimos de cara al pasado, ni les igualaremos ni podremos sobrepasarles. ¿Quién piensa en sobrepujar á un dios? Necesitamos tener la idea de que en todo lo que se ha hecho no existe lo que hay por hacer. En la contemplación de una obra, por grande que fuese, nos estancariamos siempre sin pasar de un límite. No se debe imponer así límite al arte. Toda regla de preceptiva es enojosa. El que ellos no hayan hecho una cosa no indica que no pueda hacerse, ni que todos hayan de hacerla de igual modo. Así, aun consiguiendo igual fortuna, no hariamos más que destruir la belleza del genio con la vulgarización de su obra. Tendríamos muchos Rubens, muchos Ticianos [sic], muchos Velázquez; Goethes y Wágners a granel. ¿Para qué? Basta con los que ya tenemos. Son los de nuestro siglo, los nuestros, los que necesitamos. El espíritu humano no se aviene a la inmovilidad" (Colombine, 1912, 35-36).

Francisco Alcántara escribe, en El Imparcial, en 1907, que la belleza, en la obra artística, se obtiene por medio del estudio de la naturaleza, no copiando los estilos anteriores, "porque no somos griegos, ni romanos, ni cristianos artísticamente hablando; somos modernos, debemos ser actuales y preparadores del porvenir".

Ante la obra del Cordero Mistico exclama: "Se han disfrazado con esos mantos rojos, verdes, blancos ó violeta, pero son ellos, los burgueses de Gante con sus barbas y sus facciones duras que se han prestado á servir de comparsas en una gran mascarada" (Colombine, 1912, 65). Calificar de "gran mascarada" la escena del "Cordero Místico" es, cuando menos, de un pensamiento muy alejado del concepto de la pintura flamenca, de los ideales que la hicieron posible y de la relación con su tiempo. Conocemos la "fortuna crítica" de la obra y no hay un solo crítico que no haya elogiado una de las obras que ensancha la belleza, que es patrimonio de la humanidad estética. $Y$ estas formas inmortales llámanse clásicas, así las define García Morente. Contrapunto: "Sevilla anticipo de la Gloria: Y este gran número de imágenes, que escapan con frecuencia de los templos para mezclarse a la vida de la población, familiariza con ellas al pueblo todo, y las hace vivir, no como divinidades abstractas, sino como una realidad tangible... Sevilla, vista así, es también como una antesala del cielo donde ya comienza a convivirse con la Divinidad y a gozar la gloria de los Bienaventurados" (La Esfera, 19/4/1930). Metáforas muy afortunadas, es decir, bellas.

\section{Arte y Literatura}

Valle Inclán busca en la pintura sentimientos, ideas, valores literarios, intelectualización y misterio, valores que encarna su gran amigo Julio Romero de Torres que hará un retrato a Colombine. La horaciana relación queda explícita:

"Antonio Wiertz es de los espíritus que enamoran y cautivan. Hay una multitud de grabados reveladores de desordenada fantasía... Es el primer pintor belga que se ocupa de la literatura, que intenta dar valor á una idea delicada y filosófica. Wiertz es crítico, es satírico. No porque la sátira ó la crítica resalte del asunto sin buscarla, como sucede en Teniers, sino reflexivo. Tiene caprichos hermanos de los de Goya, con el que revela un parentesco" (Colombine, 1912, 155-158).

\section{LA CRÍTICA Y EL GUSTO}

Ortega y Gasset (1962-7, 73-78) señala como una de las funciones de la crítica de arte contribuir a la formación del gusto en el público. Juan de la Encina ( La Voz, 2, julio, 1920), Francisco Alcántara, Esteban Batlle, Opisso, Manuel Rodríguez Codolá, Agrasot, son citas obligadas sobre esta cuestión. Esta actitud ante la obra de arte es la que destacamos en Colombine: "De todas las pinturas que veo en Brujas, las que más me interesan son de los primitivos flamencos... las escuelas de los Países Bajos no nos son desconocidas. En nuestro maravilloso Museo del Prado se puede estudiar á muchos maestros flamencos, Rubens y Patiniers [sic], por ejemplo, tan bien como en su patria" (Colombine, 1912, 43). Querida Carmen, de Patinir, en el Museo del Prado, sólo hay dos cuadros, La Virgen con el Niño y dos ángeles, 1518-1520, y La laguna Estigia de 1520-1524. Aquí ha podido más su pasión por España, o ha unido el recuerdo de Rubens y lo ha igualado a Patinir; observación de interés: "No han de pintar grandes cuadros para sus iglesias; los pintan para sus casas, y tienen que ser de pequeñas dimensiones, de cosas familiares" (Colombine, 1912, 281) Citamos de Hauser, 1953, el capítulo: "El Ba- 
rroco Protestante y Burgués". En el museo de Ámsterdam está la famosa Ronda de noche: "Después de contemplarla mucho tiempo absorta en su belleza, procuro analizar sus detalles y opino con los que creen que es un paseo dado de día por esa compañía de arqueros, cada una de cuyas cabezas es un retrato. Hay algunos desairados, violentos, pero ante la maravillosa expresión de vida del cuadro poemático no se piensa en su ortografía. Cuanto más se observa, más nos afirmamos en que la manifestación del alma holandesa por la pintura es siempre realista, siempre hija de la Naturaleza" (Colombine, 1912, pp. 285-286).

Casticismo estético, no populismo. Hay que compartir sentimientos, porque "Un sentimiento de arte experimentado ante un monumento, ante un cuadro, ante una estatua, en la Naturaleza ó en la audición de una partitura, necesita compartirse con el genio familiar que vive en nosotros y lejos de nosotros", entonces aflora lo telúrico, lo profundo de los sentimientos que hemos querido encerrar en cárceles de razón, por tomar una expresión de Ortega. Relata que se encuentran en Ostende:

\begin{abstract}
"Solas y desconcertadas: las frases que llegan á nosotras son extrañas. Todos hablan el flamenco; cuando los idiomas no son afines, los espíritus se encuentran muy distantes. Instintivamente mi hija y yo nos aproximamos más una á otra hablando mucho en español y escuchando nuestras voces con melodía de canto. Es este uno de esos momentos en que toma cuerpo y significación la palabra patria. Recuerdo una impresión semejante una noche en Melilla, en los desiertos caminos del Hipódromo, cuando una voz española nos preguntaba entre la sombra: "¿Quién vive?", y la emoción ahogaba la voz en la garganta al contestar: "España". ¡Melilla! ¡Bélgica! ¡España!... Un sentimiento de arte experimentado ante un monumento, ante un cuadro, ante una estatua, en la Naturaleza ó en la audición de una partitura, necesita compartirse con el genio familiar que vive en nosotros y lejos de nosotros, y es preciso arrancar esa flor del alma y entregarla al público... ¡Siempre el misterio, lo contradictorio, la paradoja!... el dualismo de los sentimientos y la razón" (Colombine, 1912, 9).
\end{abstract}

Aquí resuena en nosotros la voz egregia de Ortega y su magna pregunta que lanza al Quijote, que los que conocemos a Ortega traducimos por Cervantes: "Dios mío ¿qué es España?" (Ortega y Gasset, 1960-6, 76-77). En Regeneracionismo, incluiriamos todos los artículos de Heraldo de
Madrid con el antetítulo de "Femeninas", conectando, en la crítica de arte, con el pensamiento de Ortega, Alcántara, Saint-Aubin, Juan de la Encina.

\section{Defensa de los IDEALES ClÁsicos}

El clasicismo es reflexivo más que crítico; comentador más que analítico. Comentario sobre Ingres: "en Roma se formó su personalidad, sintió la admiración hacia el Divino Rafael y dio vida en sus lienzos á todas las bellezas del clasicismo... No necesitó críticos ni propagandas; venció sólo la belleza de sus figuras clásicas, la armoniosa corrección del dibujo, hijo de un estudio detenido, que desdeñan los genios improvisados". En Montmartre afirma que la belleza vivirá siempre. Ante el busto de Heine exclama: "Heine, enamorado de la belleza, quería perpetuar su recuerdo de Dios Griego en todo el esplendor de su divina hermosura" y le cita varias veces. De Génova destaca: "un San Sebastián de Paget; tiene una belleza apolínea, pagana y andrógina; pero es una hermosa escultura." Belleza y moral: "Tal vez si buscamos lo bello y lo bueno es porque amamos y gustamos de engalanar con estos atributos el recuerdo de nuestro amor. Decid á los que aman que vengan aquí." (Colombine, 1907, 79). La Kalokagathía, únicamente se presenta entre los griegos, es un concepto semimoral y semiestético que consiste en una fusión de la belleza y el bien, que Sócrates se encontró con esta idea en la tradición popular. Platón, El Banquete, diálogo entre Sócrates y Diotima de Mantinea (201b-d y 205d-206b): "Las mujeres lo eran todo, bellas, buenas, sabias, valientes, mucho más que los hombres" (Colombine, 1910, 6). Platón (Fedro, 246e): "Y lo divino es hermoso, sabio, bueno y todo lo semejante"... "y toda virtud afín", señalando con estas palabras que no consideraba la tríada como un conjunto completo.

La crítica de arte es considerada como esclarecedora, no como una función valorativa de la obra o del artista; por citar algunos ejemplos: Francisco Alcántara, Juan de la Encina, Eugenio d'Ors, José Camón Aznar. Ortega, en el banquete a Juan de la Encina, expresa: "En otro tiempo podía el crítico comportarse simplemente como un juez. $Y$ en este supuesto, los periódicos tendrian dos opciones: salir en tiempo presente y dejar el espacio de las críticas en blanco o no salir" (Ortega, El Sol, 13/6/1925).

ARBOR CLXXXVI EXTRA JUNIO 2010 139-147 ISSN: 0210-1963 


\section{Defensa del patrimonio artístico: el Greco}

Importancia del periodismo en la larga lucha en defensa del patrimonio artístico nacional, el Greco, necesidad de impulsar una legislación adecuada de protección del Patrimonio Artístico y cultural, protección de los bienes en poder de la Iglesia. Anticlericalismo latente y militante. La actuación, por parte de Colombine, se inscribe en las campañas, que se vienen sucediendo en la prensa, para salvar los cuadros de la capilla de San José. Desde Heraldo de Madrid, Saint-Aubin, respetado por todos los críticos de arte, viene desarrollando una intensa lucha que se remonta a los primeros años del siglo XX. El Globo, en 1904, adelanta la noticia de que el Cabildo de la catedral de Toledo intenta vender unos magníficos cuadros del Greco. Se suman, a la denuncia, todos los diarios de Madrid, entre los que destacamos La Época, en El Imparcial a Mariano de Cávia, El Norte de Castilla se hace eco del artículo de Cávia, Saint-Aubin, diputado en las Cortes, publica, en Heraldo de Madrid, continuas críticas con un título genérico "Filón que se agota", y, debemos añadir, artículos de Tomás Borrás, Ángel Vegue y Goldoni desde las páginas de El Mundo, Alcántara en El Imparcial, Manuel Bueno en El Diluvio de Barcelona citando, también, a Mariano de Cávia, siempre un referente en estos pleitos. Sain-Aubin, en 1906, titula "iAlerta!", ante la posibilidad de venta de El Entierro del Señor de Orgaz; interviene Luis de Armiñán, Sentenach desde la Academia de Bellas Artes de San Fernando, y, por fin, Rafael Doménech, uno de los más prestigiosos críticos, historiador y académico de San Fernando, desde El Liberal, reclama leyes, si no las hay, que protejan nuestro patrimonio (y cuenta una anécdota muy ilustrativa: "Carlyle preguntaba a los ingleses qué preferirían: perder el imperio de las Indias o no haber tenido á Shakespeare; y Carlyle, por boca de todos los súbditos de S.M. Británica, contestaba que era preferible lo primero pues el imperio de las Indias un día u otro se perderá, pero sin Shakespeare no existiría el pueblo inglés") La venta de los cuadros de la capilla de San José, de Toledo, suscita tanta indignación que Diario Universal, en noviembre de 1906, inserta la noticia de que en el Congreso Saint-Aubin hace una pregunta al ministro de Instrucción pública; $L a$ Época, publica que se intenta detener el expolio; El Globo, que "salió para Toledo el subsecretario de Instrucción pública". A partir de este momento entramos en una historia rocambolesca, esquizofrénica y surrealista. Podemos afirmar que, después de haber leído todo lo referente al asunto, no entendemos nada. Colombine, en octubre de 1907, desde
Toledo, entra en este penoso suceso de anticuarios ( $\mathrm{Co}$ lombine, 1921, 101 y 180), monjas, curas, patronos y demás chamarileros; Carmen, recogiendo "el suelto que publica $E I$ Imparcial llegado hoy al Heraldo sobre la venta, probablemente realizada de dos cuadros del Greco pertenecientes a una iglesia de la ciudad", escribe un pequeño suelto, que por el texto se deduce que está en Toledo, $y$, muy periodísticamente añade, "inmediatamente me he puesto en camino para visitar a diversas personalidades y demandar informes exactos. Escribiré cuanto haya.-C". Colombine, el 11 de octubre, firma una crónica, en Heraldo de Madrid, con el título "Los cuadros del Greco", con una entradilla que sitúa al lector ante el problema, la continua venta de obras en poder de iglesias y conventos de Toledo. Es un documento de gran importancia, al igual que otras de sus crónicas, difícil de soslayar en el estudio sobre la venta de obras del Greco, particularmente, y un referente en la defensa de nuestro patrimonio artístico. El viernes 18 de octubre de 1907 publica sus gestiones, se entrevista con el Cardenal de Toledo: "Confieso que, acostumbrada a contemplar la vulgaridad del clero, me sentí desde el primer momento impresionada por la sencilla amabilidad del cardenal Sancha... después pasamos a visitar al gobernador, señor marqués de Fuensanta de Palma, que nos recibió con exquisita amabilidad y galantería... el amable alcalde de Toledo poco pudo añadir a los datos ya recogidos." El 1 de noviembre escribe, no exenta de frustración y desaliento, que el ministro de Instrucción pública parece poner punto en el Congreso a la discusión que los diputados amantes del Arte y de las glorias de la nación sostienen. El Mundo publica un Manifiesto de la "Institución Libre de Enseñanza" con este encabezamiento: "A la Nación Española". No faltan las notas cultas y eruditas y la defensa del patrimonio de España hace su brillante aparición de la pluma de Cossío, sin duda redactor del manifiesto. Podemos afirmarlo, la campaña de la prensa (destacamos los artículos de Colombine) ha dado sus frutos, y España parece que intenta recobrar parte de su conciencia. El deseo, y la necesidad, de fundar un museo del Greco, que Colombine relata, se llevará a feliz término gracias a la acción del Marqués de la Vega Inclán. Años después, con motivo del centenario escribe un bello artículo que titula: "Las Mujeres del Greco" (Heraldo de Madrid, 6/4/1914): "No es mi ánimo entrar en una crítica de la pintura del Greco. Es el alma, que ha quedado viva en los ojos inquietantes de sus mujeres, lo que mueve hoy mi interés... las mujeres del Greco son de la misma familia que aquellos hombres cetrinos, fuertes, angulosos, férreos, severos. Aparece, bri- 
Ilantemente utilizado, el "tertium comparationis", entre el Greco y Goya centrado en la mujer, en su dignidad, uno de los objetivos de su lucha y de su vivir:

"No son estas mujeres de la misma familia, recia y fuerte, ni de la misma raza, que las alegres, juguetonas y frivolas mujercitas de Goya. Estas del Greco, dentro de su naturalismo, son esencialmente místicas e idealistas; esas figuras tan serenas... con su tez pálida, sus labios marchitos, sus facciones acentuadas, destacadas del fondo negro del lienzo, estas mujeres quieren contarnos sus historias, decirnos sus anhelos... revelarnos tal vez todo el misterio y el secreto del alma femenina."

Calificamos de naturalismo del espíritu la pintura del Greco. La mujer, el arte, el Greco. ¡Qué cerca estuvo de descubrir el misterio a través de estos intermediarios!

\section{NOTAS}

1 En sus artículos, y libros de viajes, nos deja un continuo ataque a la Iglesia bien dosificado: "El monasterio de Loyola y los recuerdos de San Ignacio. Se comprende cómo, entre aquellos montes, se forjó á martillazos la soberbia voluntad de hombre tan nefasto..." (Colombine, 1910, 10); "El Cristo de Cellini es la divinidad vinculada en un hombre, tal como la explica el mito de la Encarnación..." (Colombine, 1910, 12); "Burgos. ¿Qué necesidad impulsa á los hombres á orar? ¿No bastan la belleza, el Arte y la Ciencia para satisfacer el espíritu? Quisiera conocer todos los pensamientos que hay debajo de una toca monjil en caso de que haya alguno" (Colombine, 1907, 14); Pompeya, templo de Isis: "Se ve la escala subterránea por donde entraban los sacerdotes para confeccionar milagros, como después hicieron y aun hacen los sacerdotes católicos" (Colombine, 1907, 289) y añade notas sectarias a p.p. de Ferrándiz que hace suyas; en Génova, la riqueza de sus iglesias la hace exclamar "¡Cuánto capital muerto!".

\section{BIBLIOGRAFÍA}

Aristóteles (1988): Retórica, Barcelona, Gredos.

Recibido: 14 de mayo de 2010 Aceptado: 7 de junio de 2010
Burgos Seguí, Carmen de (1907): Por Europa, Barcelona, Casa Editorial Maucci.

Burgos Seguí, Carmen de (1910): El veneno del arte, Madrid, Los Contemporáneos.

Burgos Segui, Carmen de (1912): Cartas sin destinatario, Valencia, Ed. Sempere.

Burgos Segui, Carmen de (1921): Los anticuarios, Madrid, Los Contemporáneos.

Gómez Aparicio, Pedro (1974): Historia del periodismo español. De las guerras coloniales a la Dictadura, Madrid, Editora Nacional.

Hauser, Arnold (1961): Introducción a la Historia del Arte, Madrid, Guadarrama.

Hauser, Arnold (1967): Historia Social de la Literatura y el Arte, Madrid, Guadarrama.

Francastel, Pierre (1967): La figure et le lieu, París, Gallimard.

Francastel, Pierre (1988): La realidad figurativa, I., Barcelona, Paidós.

Núñez Rey, Concepción (2005): Carmen de Burgos, Colombine, Sevilla, Fund. J-M. Lara.

Ortega y Gasset, José (1914): Meditaciones del Quijote, Madrid, Residencia de Estudiantes; Revista de Occidente (Col. "El Arquero")

Ortega y Gasset, José (1962-7): La deshumanización del arte: "Sobre la crítica de arte", Madrid, Revista de Occidente (Col. "El Arquero")

Pächt, Otto (1986): Historia del arte y metodologías, Madrid, Alianza.

Platón (2008): Fedro, Madrid, Gredos.

Platón (1998): El Banquete, Madrid, Tecnos y Gredos. 